\title{
Hierarchical Porous Molybdenum Carbide Based Nanomaterials for Electrocatalytic Hydrogen Production
}

\author{
Yan Liu ${ }^{1}$, Juanjuan Huo ${ }^{1}$, Jiaojiao Guo ${ }^{1}$, Li Lu ${ }^{1}$, Ziyan Shen ${ }^{1}$, Weihua Chen ${ }^{2}$, Chuntai Liu ${ }^{2}$ \\ and Hao $\mathrm{Liu}^{1,3 *}$ \\ ${ }^{1}$ Joint International Laboratory on Environmental and Energy Frontier Materials, School of Environmental and Chemical \\ Engineering, Shanghai University, Shanghai, China, ${ }^{2}$ Key Laboratory of Materials Processing and Mold (Zhengzhou \\ University), Ministry of Education, Zhengzhou, China, ${ }^{3}$ Centre for Clean Energy Technology, School of Mathematical and \\ Physical Sciences, Faculty of Science, University of Technology Sydney, Sydney, NSW, Australia
}

The electrocatalytic hydrogen evolution reaction (HER) for the preparation of hydrogen fuel is a very promising technology to solve the shortage of hydrogen storage. However, in practical applications, HER catalysts with excellent performance and moderate price are very rare. Molybdenum carbide $\left(\mathrm{Mo}_{x} \mathrm{C}\right)$ has attracted extensive attention due to its electronic structure and natural abundance. Here, a comprehensive review of the preparation and performance control of hierarchical porous molybdenum carbide $\left(\mathrm{HP}-\mathrm{Mo}_{\mathrm{x}} \mathrm{C}\right)$ based catalysts is summarized. The methods for preparing hierarchical porous materials and the regulation of their HER performance are mainly described. Briefly, the $\mathrm{HP}-\mathrm{Mo}_{\mathrm{x}} \mathrm{C}$ based catalysts were prepared by template method, morphology-conserved transformations method, and secondary conversion method of an organic-inorganic hybrid material. The intrinsic HER kinetics are enhanced by the introduction of a carbon-based support, heteroatom doping, and the construction of a heterostructure. Finally, the future development of $\mathrm{HP}-\mathrm{Mo}_{\mathbf{x}} \mathrm{C}$ based catalysts is prospected in this review.

*Correspondence:

Hao Liu

hao.liu@uts.edu.au

Specialty section:

This article was submitted to Nanoscience,

a section of the journal

Frontiers in Chemistry

Received: 21 March 2020 Accepted: 23 April 2020 Published: 19 May 2020

Citation:

Liu Y, Huo J, Guo J, Lu L, Shen Z, Chen W, Liu C and Liu H (2020) Hierarchical Porous Molybdenum Carbide Based Nanomaterials for Electrocatalytic Hydrogen Production

Front. Chem. 8:426.

doi: $10.3389 /$ fchem.2020.00426
Keywords: hierarchical structure, electrocatalytic reaction, hydrogen production, porous structure, molybdenum carbide

\section{INTRODUCTION}

Hydrogen is a green energy with high energy density and excellent combustion performance (Martinez et al., 2019; Yang et al., 2019). HER is a key reaction for the renewable production of hydrogen. However, the actual reaction process is inefficient. In order to increase the conversion efficiency of the reaction process and reduce the reaction overpotential, a certain amount of catalyst is usually used (Chen et al., 2018; Huo et al., 2019; Ling et al., 2019). The ideal electrocatalyst for the HER is platinum (Pt) or other precious metals, but its application is severely limited by low richness and high cost (Khaselev and Turner, 1998; Nong et al., 2018).

$\mathrm{Mo}_{\mathrm{x}} \mathrm{C}$ has a wide range of applications in the fields of energy storage and conversion, for example, hydrodesulf'urization, denitrification (Wang et al., 2007; Ma et al., 2018), methanol reforming, electrolyte, etc. (Gao et al., 2010; Lin et al., 2017b; Yang et al., 2020). Density functional theory (DFT) calculations of carbides show that the hybridization of metal $\mathrm{d}$ orbitals with carbon $\mathrm{s}$ and $\mathrm{p}$ orbitals causes wider d-band structure, showing 
a d-band structure similar to Pt (Zhao et al., 2019b). This makes $\mathrm{Mo}_{\mathrm{x}} \mathrm{C}$ a promising alternative to precious metal catalysts. Conventional $\mathrm{Mo}_{\mathrm{x}} \mathrm{C}$ based catalysts generally have no voids or low porosity, resulting in low active surface area and poor wettability. Designing hierarchical porous micro/nanostructures can solve these problems. The hierarchical porous material has multi-stage pore structure, which is micropores $(<2 \mathrm{~nm})$, mesopores $(2-50 \mathrm{~nm})$ and macropores $(>50 \mathrm{~nm}$ ) (Li et al., $2019 b)$. The properties and functions of a material depend on the characteristics of its structure, such as pore size, shape, porosity, etc. (Ryoo, 2019). In general, the presence of micropores provides a large surface area, mesoporous, and macroporous structures are effective in improving electrolyte penetration and promoting ion diffusion. The structure of hierarchical porous materials is usually assembled from nanoscale units by van der Waals forces, ionic bonds, covalent bonds and hydrogen bonds. The preparation of $\mathrm{HP}-\mathrm{Mo}_{\mathrm{x}} \mathrm{C}$ based catalysts prevents the agglomeration of the nanoparticles, greatly increasing the specific surface area of the material and exposing more active sites (Kim et al., 2020). Compared with other non-precious metal catalysts, $\mathrm{HP}-\mathrm{Mo}_{\mathrm{x}} \mathrm{C}$ has a hierarchical porous structure on the macro scale and a d-band structure similar to Pt on the micro scale, which makes it exhibiting unique advantages.

This review focuses on the preparation and performance of $\mathrm{HP}-\mathrm{Mo}_{\mathrm{x}} \mathrm{C}$ based catalysts, including soft-hard template method, morphology-conserved transformations, secondary conversion of organic-inorganic hybrid materials to construct catalysts with specific morphology. By introducing other conductive carriers, heterogeneous doping and construct heterostructured hybrids to optimize the HER performance of $\mathrm{HP}-\mathrm{Mo}_{\mathrm{x}} \mathrm{C}$ based catalysts. Table 1 shows the performance parameters of each catalyst mentioned in this article. Finally, an overview of the future development of $\mathrm{HP}-\mathrm{Mo}_{\mathrm{x}} \mathrm{C}$ based electrocatalysts is outlined.

\section{CONSTRUCTION OF HP-MOXC WITH SPECIAL MORPHOLOGY}

$\mathrm{HP}-\mathrm{Mo}_{\mathrm{x}} \mathrm{C}$ based catalysts with a special morphology have many excellent properties such as rapid mass transfer, ultra-high surface area, controlled pore size and nano-effects (Niu et al., 2019; Wang et al., 2019b). Therefore, it is becoming more and

TABLE 1 | Summary of HER performance of $\mathrm{Pt} / \mathrm{C}$ and various catalysts appearing in the article.

\begin{tabular}{|c|c|c|c|c|c|c|c|}
\hline & Method & Catalyst & $\eta_{\text {onset }}(\mathrm{mv})$ & $\eta_{10}$ (mv) & Electrolyte & $\begin{array}{c}\text { Tafel slope (mv } \\
\left.\operatorname{dec}^{-1}\right)\end{array}$ & References \\
\hline \multirow[t]{8}{*}{ Preparation } & Template method & uf- $\mathrm{Mo}_{2} \mathrm{C} / \mathrm{CF}$ & 49 & 184 & Acidic & 71 & Kou et al., 2018 \\
\hline & & $\mathrm{Mo}_{2} \mathrm{C} / \mathrm{MCS}$ & 73 & 134 & Alkaline & 51 & Yuan et al., 2019 \\
\hline & $\begin{array}{l}\text { Morphology-conserved } \\
\text { transformations }\end{array}$ & Nano MoC@GS & 84 & 132 & Acidic & 46 & Shi et al., 2016 \\
\hline & & $\begin{array}{l}\text { Porous MoCx } \\
\text { nano-octahedrons }\end{array}$ & 25 & 142 & Acidic & 5 & Wu et al., 2015 \\
\hline & & & 80 & 151 & Alkaline & 59 & \\
\hline & & $\mathrm{MoC}-\mathrm{Mo}_{2} \mathrm{C} / \mathrm{PNCDS}$ & 121 & 1 & Alkaline & 60 & Lu et al., 2019 \\
\hline & $\begin{array}{l}\text { Secondary conversion } \\
\text { of organic-inorganic } \\
\text { hybrid materials }\end{array}$ & $\mathrm{np}-\mathrm{Mo}_{2} \mathrm{C} \mathrm{NW}$ & 70 & $\backslash$ & Acidic & 1 & Liao et al., 2014 \\
\hline & & $\mathrm{P}-\mathrm{Mo}_{2} \mathrm{C} \mathrm{NWs}$ & 42 & 89 & Acidic & 42 & Shi et al., 2017 \\
\hline \multirow[t]{11}{*}{ Regulation } & $\begin{array}{l}\text { Introducing other } \\
\text { conductive carriers }\end{array}$ & $\mathrm{Mo}_{2} \mathrm{C}-\mathrm{RGO}$ & 70 & 130 & Acidic & 54 & Pan et al., 2014 \\
\hline & & $\mathrm{Mo}_{2} \mathrm{C} / \mathrm{G}$ & $\backslash$ & 175 & Acidic & 88 & Huang et al., 2019c \\
\hline & & & $\backslash$ & 200 & Alkaline & 82 & \\
\hline & & $\mathrm{Mo}_{2} \mathrm{C} @ \mathrm{NC}$ nanomesh & $\backslash$ & 37.5 & Acidic & 33.7 & Cheng et al., 2018 \\
\hline & Doping & $\mathrm{Mo}_{2} \mathrm{C}-\mathrm{N}-\mathrm{CNFS}$ & 105 & 192 & Acidic & 70 & Wu et al., 2016 \\
\hline & & $\mathrm{Ni} / \mathrm{Mo}_{2} \mathrm{C}-\mathrm{NCNFS}$ & 29 & 143 & Alkaline & 57.8 & Li et al., 2019b \\
\hline & & $\mathrm{NP}-\mathrm{MO}_{2} \mathrm{C}$ & $\backslash$ & 210 & Acidic & 64 & Wang et al., 2018a \\
\hline & $\begin{array}{l}\text { Hierarchical porous } \\
\text { molybdenum } \\
\text { carbide-based } \\
\text { heterostructure }\end{array}$ & $\mathrm{Mo}-\mathrm{Mo}_{2} \mathrm{C}$ & 67 & 150 & Acidic & 55 & Dong et al., 2018 \\
\hline & & $\mathrm{Mo}_{2} \mathrm{C} / \mathrm{CC} @ \mathrm{C}$ & $\backslash$ & 122 & Acidic & 43.8 & Huang et al., 2019a \\
\hline & & $\mathrm{Pt} / \mathrm{C}$ & 0 & 28 & Acidic & 33 & \\
\hline & & & 0 & 43 & Alkaline & 113 & \\
\hline
\end{tabular}

$\eta_{10}$, overpotentials to drive the current densities of $10 \mathrm{~mA} \mathrm{~cm}^{-2}$.

$\eta_{\text {onset, }}$ oneset overpotential. 
more important to construct various forms of nano-catalytic materials. The use of nanotechnology makes it possible to expose as many active sites as possible during electrocatalysis, thereby improving HER performance (Hou et al., 2019). However, how to control the structural size and shape of materials still poses great challenges in the current research process.

\section{Template Method to Construct HP-Mox C Based Catalysts}

The template method is one of the effective methods for preparing hierarchical porous materials, and can effectively control the morphology, particle size, and structure during the preparation process (Huang et al., 2019b; Zhao et al., 2019a). It is mainly divided into hard template method and soft template method. The hard template has rigid structure and specific morphology, and its morphology is copied into the target material by nano-replication technology. The obtained product has good dispersibility, controllable pore size and has been widely used (Chen et al., 2019; Feng et al., 2019).

Due to the stability of the hard template structure, the precursors are often used as "microreactor" in the synthesis process (Liu et al., 2019). The colloidal crystal (Thompson et al., 2019) contains a large amount of monodisperse colloidal particles, which are uniformly arranged in three dimensions. Using colloidal crystals as sacrificial hard templates, ordered and monodisperse pores can be introduced into the material. Kou et al. (2018) prepared hierarchical porous molybdenum carbide nanocrystals (uf- $\mathrm{Mo}_{2} \mathrm{C} / \mathrm{CF}$ ) with efficient HER performance by using uniformly-sized $\mathrm{SiO}_{2}$ microspheres as confined template (Figure 1A). Average size of nanocrystals is $<2 \mathrm{~nm}$. This

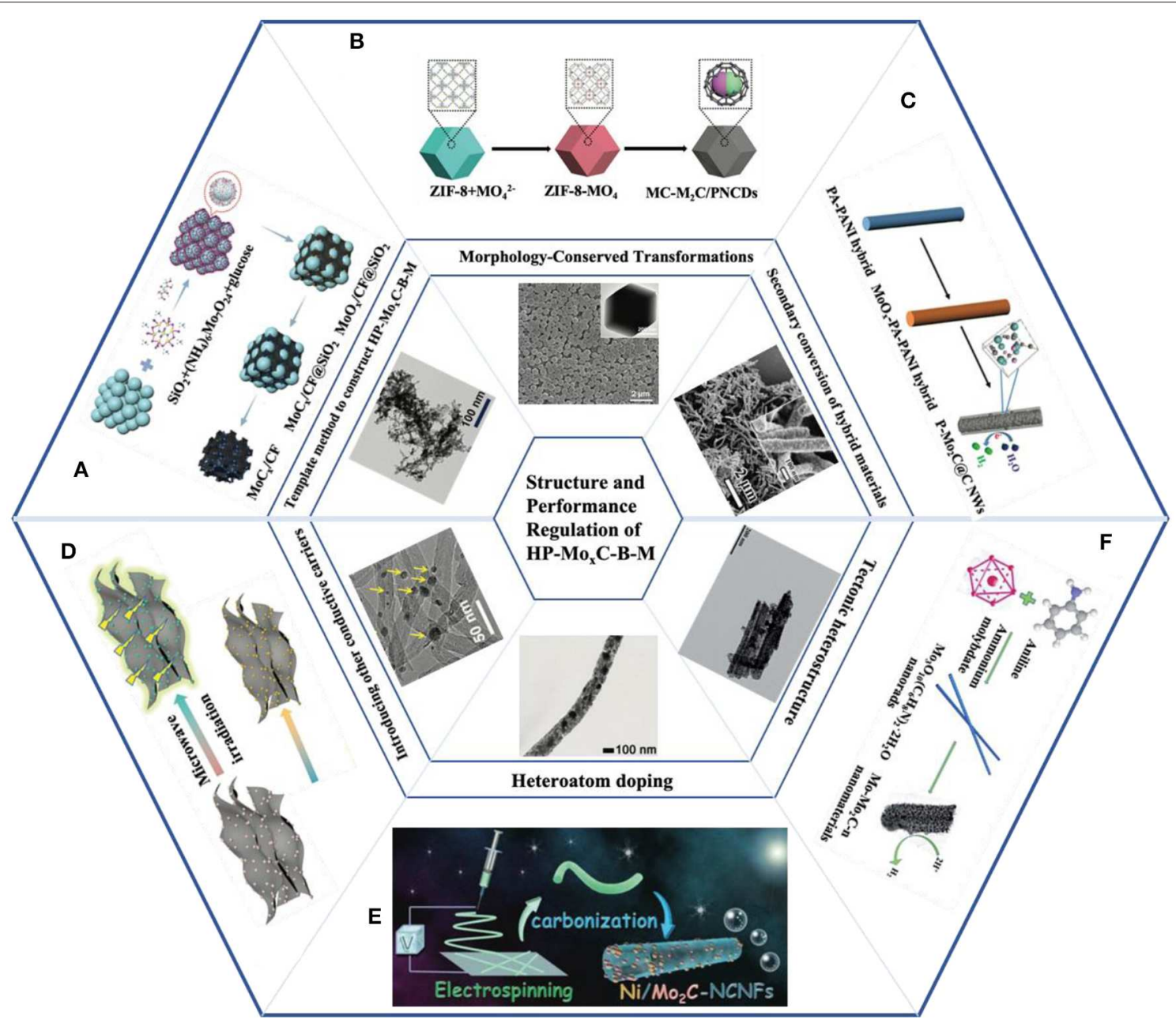

FIGURE 1 | Schematic illustration of synthesis and structures of various $\mathrm{HP}-\mathrm{Mo}_{x} \mathrm{C}$ based catalysts: (A) Schematic synthesis route and TEM image of the uf-Mo $2 \mathrm{C} / \mathrm{C}$. Reprinted with permission from Kou et al. (2018) with permission from WILEY-VCH. (B) Schematic synthesis route and SEM/TEM images of the MoC-Mo $2 \mathrm{C} / \mathrm{PNCDs}$. Reprinted with permission from Lu et al. (2019) with permission from WILEY-VCH. (C) Schematic synthesis route and SEM image of the P-Mo 2 CC NWs. Reprinted with permission from Shi et al. (2017) with permission from Royal Society of Chemistry. (D) Schematic synthesis route and HR-TEM image of the Mo 2 C/G. Reprinted with permission from Huang et al. (2019c) with permission from WILEY-VCH. (E) Schematic synthesis route and TEM image of the Ni/Mo $2 \mathrm{C}-\mathrm{NCNFs}$. Reprinted with permission from Li et al. (2019b) with permission from WILEY-VCH. (F) Schematic synthesis route and TEM image of the Mo-Mo $2 \mathrm{C}$. Reprinted with permission from Dong et al. (2018) with permission from Royal Society of Chemistry. 
3D hierarchical porous structure enables a large number of mass transfer channels, high density of active sites, and high electrical conductivity, thereby providing a highly efficient and stable catalytic performance. Soft template method has no fixed structure and morphology. Soft templating agent mainly forms an organic phase with a certain morphology through intermolecular or intramolecular interaction forces (Xue et al., 2019; Zhang et al., 2019). In the process of synthesis, soft templating agent interacts with the inorganic phase to form an organic-inorganic phase with a certain morphology, thereby achieving the purpose of directional synthesis of nanomaterials. Yuan et al. (2019) used the precursor spheres formed by F127 and resoled phenolic resin to limit the growth of molybdenum carbide, and obtained ultra-small $\mathrm{Mo}_{2} \mathrm{C}$ particles encapsulated in situ in mesoporous carbon spheres ( $\left.\mathrm{Mo}_{2} \mathrm{C} @ \mathrm{MCS}\right)$. The ultrasmall particle size exposes more active sites, and the presence of a carbon substrate greatly reduces the resistance of the catalyst, thereby exhibiting excellent electrocatalytic performance in an alkaline medium (Liu et al., 2018; Huang et al., 2019d). This study provides an effective strategy for the synthesis of a $\mathrm{Mo}_{\mathrm{x}} \mathrm{C} @ \mathrm{C}$ catalyst.

\section{Morphology-Conserved Transformations}

Although the template method can effectively control the morphology and pore size of the catalyst, the synthesis and the removal process of the template cause a lot of waste of resources and increase in cost, which hinders its application. The morphology-conserved transformations method has been developed as a simple and effective synthesis route (Tan et al., 2012). This method usually consists of two steps: first, a hierarchical porous metal intermediate compound is constructed and then converted into a carbon material by specific method. Metal organic frame materials (MOF) have become one of the most promising candidate precursors for the preparation of hierarchical porous materials due to their advantages such as uniform and controllable pore structure and large specific surface area (Dhakshinamoorthy et al., 2019; Garzón-Tovar et al., 2019). Shi et al. (2016) synthesized a highly active and stable MoC encapsulated by graphitized carbon shell (nanoMoC@GS) electrocatalyst by in-situ carburization of Mobased MOF, achieving "atomic-level contact" between Mo and organic species. The rich organic matter in the MOF generates a porous conductive carbon shell layer, which improves the ion transmission to the medium. Wu et al. (2015) adopted the "MOFs-assisted synthesis strategy" synthesized Cu-based MOFs (NENU-5) with $\mathrm{MoC}_{\mathrm{x}}$ nano-octahedral hydrogen evolution electrocatalysts with excellent HER activity. Recently, they used an ion exchange method to convert $\mathrm{MO}_{4}^{2-}$ groups by employing an exchange reaction between a zinc-based imidazole MOF (ZIF8 ) and a metal salt $\left(\mathrm{Na}_{2} \mathrm{MO}_{4}, \mathrm{M}=\mathrm{Mo}\right.$ or $\left.\mathrm{W}\right)$ in an organic solvent (Lu et al., 2019) (Figure 1B). The $\mathrm{MO}_{4}^{2-}$ group replaces the $\mathrm{Zn}$ (imidazolate) ${ }_{4}^{2-}$ group in ZIF-8, thereby effectively dispersing and fixing the metal source uniformly in the ZIF-8 framework $\left(\mathrm{Mo}_{\mathrm{x}} \mathrm{C} / \mathrm{PNCD}\right)$. Due to the structural advantages of ZIF-8, the low boiling point of $\mathrm{Zn}$ and the controlled exchange of $\mathrm{MO}_{4}^{2-}$, ultrafine carbide nanocrystals with a porous nitrogen-doped carbon dodecahedron were successfully obtained. And achieve effective control of the carbide phase and composition, which not only provides a more stable active site, but also promotes electron transport during the HER process.

\section{Secondary Conversion of Organic-Inorganic Hybrid Materials (SC-OI-M)}

Currently, there are few simple and diverse synthesis methods for new MOF materials, which greatly limits their development and application. In addition, conventional MOFs only have micropores and lack transmission channels such as mesopores and macropores, which will greatly reduce their transmission efficiency in the catalytic process. SC-OI-M refers to the integration of two counterparts into a single structure at the nanoscale (Wang et al., 2018b; Li et al., 2019a). This nano-scale single structure provides a periodic organic-inorganic structure, which has a "barrier effect" between the Mo sources during the high-temperature carbonization process, which can effectively prevent and promote the formation of nanostructures during high-temperature sintering. The hybrid materials generate a large amount of reducing gases such as $\mathrm{CH}_{\mathrm{x}}, \mathrm{CO}$, and $\mathrm{H}_{2}$ under high temperature decomposition to achieve the in-situ conversion of molybdenum carbide. The structure, morphology and composition of the synthesized molybdenum carbide have excellent controllability. Liao et al. (2014) synthesized nanoporous $\mathrm{Mo}_{2} \mathrm{C}$ Nanowires (np- $\mathrm{Mo}_{2} \mathrm{C}$ NWs) by pyrolyzing $\mathrm{MoO}_{\mathrm{x}} /$ amine hybrid precursors with sub-nanometer periodic structure. This became the beginning of the "SC-OI-M" for the development of highly active hydrogen evolution catalysts. $\beta$ $\mathrm{Mo}_{2} \mathrm{C}$ has outstanding HER performance, but it often exhibits excessive hydrogen absorption capacity, which restricts the desorption step of hydrogen atoms in HER (i.e., Heyrovsky/Tafel) (Wan et al., 2014). Shi et al. (2017) used electrostatic assembly to prepare a three-component hybrid precursor of $\mathrm{MoO}_{\mathrm{x}}{ }^{-}$ phytic acid-polyaniline. P-doped $\beta-\mathrm{Mo}_{2} \mathrm{C}$ composite nanowire electrocatalyst (P-Mo $2 \mathrm{C} @ \mathrm{C}$ NW) was obtained after high temperature carbonization (Figure 1C). On the nanometer scale, the uniform ultra-small $\beta-\mathrm{Mo}_{2} \mathrm{C}$ particles provide abundant exposed catalytically active sites, and the structure of the one-dimensional nanowire facilitates the radial conduction of electrons. The resulting graphitized carbon greatly improves the overall conductivity and stability of the catalyst. At the atomic scale, the introduction of $\mathrm{P}$ atoms effectively increases the electron cloud density of the $\beta-\mathrm{Mo}_{2} \mathrm{C}$ Fermi level, and introduces steric hindrance effects, effectively weakens the Mo$\mathrm{H}$ bond, reduces the $\Delta \mathrm{GH}^{*}$ of $\beta-\mathrm{Mo}_{2} \mathrm{C}$. Experimental and theoretical calculations show that suitable P doping (2.9\%) can effectively balance the Volmer and Heyrovsky/Tafel processes in the HER and optimize the intrinsic activity of $\beta-\mathrm{Mo}_{2} \mathrm{C}$ for hydrogen evolution. Based on the controllability of this method, the researcher also proposed a series of electronic and spatial structure control methods. The formation of heterostructures such as by Co atom doping (Lin et al., 2016a), MoC- $\mathrm{Mo}_{2} \mathrm{C}$ (Lin et al., 2016b), and $\mathrm{Fe}_{3} \mathrm{C}-\mathrm{Mo}_{2} \mathrm{C}$ (Lin et al., 2017a), the fine control of the surface and structure of $\beta-\mathrm{Mo}_{2} \mathrm{C}$ was realized, and the electrocatalytic performance was optimized. 


\section{REGULATE THE CATALYTIC PERFORMANCE OF HP-MoxC BASED CATALYSTS}

The key to construct a high-activity catalyst is using the advantages of $\mathrm{HP}-\mathrm{Mo}_{\mathrm{x}} \mathrm{C}$ catalyst with high electronic conductivity and large specific surface area, combined with the regulation of active sites. There are two basic principles in the regulation of catalyst performance namely increasing the active site and enhancing the intrinsic activity of the material. For the former, it can be achieved by porous structure; for the latter, it can be achieved by heteroatom doping and constructing heterostructure.

\section{Introducing Other Conductive Carriers}

Enriched active sites of sufficient unsaturated Mo and C atoms promote intimate contact between the electrolyte and the electrode material, thereby enhancing catalytic performance (Wang et al., 2019a; Cui et al., 2020). The introduction of a suitable matrix to form a strong coupling toward the catalyst can improve the intrinsic catalytic activity of $\mathrm{Mo}_{\mathrm{x}} \mathrm{C}$, and also increase the conductivity of the catalyst due to the synergistic effect in the hybrid nanostructure, and hance, finally harvest desired electrochemical performance (Amrute1 et al., 2019; Xiong et al., 2019; Zhao et al., 2019c).

Up to now, a series of carbon materials such as reduced graphene oxide and carbon nanotubes have been used for supporting molybdenum carbide particles because of their large surface area and excellent electronic conductivity (Huang et al., 2019c; Li et al., 2019d; Wang et al., 2019e; Yu et al., 2019). Pan et al. (2014) used glucose as GO stabilizer, carbon source and reducing agent to prepare $\mathrm{Mo}_{2} \mathrm{C}$ nanoparticles grown on reduced graphene oxide $\left(\mathrm{Mo}_{2} \mathrm{C}-\mathrm{RGO}\right)$, which showed excellent HER electrocatalytic activity. Huang et al. (2019c) developed a new technology for microwave-assisted ultrafast preparation of high performance carbon supported molybdenum carbide catalysts $\left(\mathrm{Mo}_{2} \mathrm{C} / \mathrm{G}\right)$ (Figure 1D). They impregnated the carbon support with ammonium molybdate solution and irradiated it with microwave to obtain a carbon-supported molybdenum carbide catalyst. The carbon carrier material acts as an absorbing medium to promote in-situ rapid heating of the material, and a carbon source for forming $\mathrm{Mo}_{2} \mathrm{C}$. This method can be applied to a variety of large-scale production of carbon carriers, including graphene, carbon nanotubes, commercial carbon black, and carbon fiber, etc. The in situ formation of the carbon support ensures a tight interfacial contact between the active material and the conductive substrate, thereby promoting rapid charge transfer between the substrate and the active material (Zhang et al., 2018; Han et al., 2019; Hou et al., 2019). Finding a way to synthesize molybdenum carbide/carbon support composites in one step is very valuable (Hsieha et al., 2019; Wu et al., 2019). Cheng et al. (2018) synthesized a $1 \mathrm{~nm}$-sized molybdenum carbide nanoparticle in a carbon $\left(\mathrm{Mo}_{2} \mathrm{C} @ \mathrm{NC}\right)$ nanomesh through hydrothermal treatment, using dicyandiamide as a carbon and nitrogen source, ammonium molybdate as a molybdenum source. During the hydrothermal process, the intermolecular hydrogen bonding is used to self-assemble into band structure to limit the growth of particles. This mesoporous ribbon nanoweb structure provides a high specific surface area and a rich active site, greatly reduced the energy barrier. This material has excellent HER/ORR performance compared to other materials. This work demonstrates a simple template-free strategy for the synthesis of highly efficient non-precious metal catalysts with large specific surface areas. It also shows the possibility of replacing platinum-based catalysts with molybdenum carbide materials from theoretical to experimental evidence.

\section{Doping}

The performance of the catalyst can also be controlled by doping. Heteroatom doping can be combined with addition of conductive support to enhance the intrinsic activity of the materials besides increasing the active site of the catalysts. The doping of heteroatoms into the lattice of the catalyst can adjust the electron and surface structure of the material, thereby affecting the adsorption free energy of the reaction intermediate on the surface, and improving the catalytic efficiency (Jia et al., 2017; Guo et al., 2019; Li et al., 2019a). At present, non-metal atoms (N, S, P, B, etc.), transition metals ( $\mathrm{Fe}, \mathrm{Co}, \mathrm{Ni}, \mathrm{Zn}$, etc.) are introduced to replace $\mathrm{Mo} / \mathrm{C}$ atoms in $\mathrm{Mo}_{\mathrm{x}} \mathrm{C}$. It can adjust the intrinsic electron configuration of molybdenum carbide and improve the conductivity (Li et al., 2019c; Wang et al., 2019c,f; Zhong et al., 2019).

Nitrogen-doped nano-carbon support plays an important role in improving electrocatalytic activity ( $\mathrm{Wu}$ et al., 2018a; Lyu et al., 2019). Wu et al. (2016) synthesized ultrafine $\mathrm{Mo}_{2} \mathrm{C}$ nanoparticles embedded within bacterial cellulose-derived 3D Ndoped carbon nanofiber networks ( $\left.\mathrm{Mo}_{2} \mathrm{C} @ \mathrm{~N}-\mathrm{CNFs}\right)$. Theoretical calculations demonstrate that excellent HER activity results from a strong synergistic effect between $\mathrm{Mo}_{2} \mathrm{C}$ nanocatalyst and $\mathrm{N}$ CNF. Transition metal dopants (Ni, Co, Fe, etc.) can improve catalytic performance by adjusting the electronic configuration, creating new active sites and activating surrounding sites ( $\mathrm{Wu}$ et al., 2018b; Cao et al., 2019). Li et al. (2019b) synthesized $\mathrm{Ni} / \mathrm{Mo}_{2} \mathrm{C}$ nitrogen-doped carbon nanofibers (Ni/Mo $2 \mathrm{C}-\mathrm{NCNFs}$ ) by using the electrospinning method (Figure 1E). Synergistic effect between $\mathrm{Ni}$ and $\mathrm{Mo}_{2} \mathrm{C}$ nanoparticles, high conductivity, large electrochemical active surface area and effective $\mathrm{N}$ doping significantly promote HER and OER due to strong hydrogen binding energy on $\mathrm{Mo}_{2} \mathrm{C}$ and high conductivity of Ni. This work provides a facile and effective way to produce low cost and high performance dual functional electrocatalysts for efficient overall water splitting. Since a single heteroatom doping has been shown to improve the catalytic performance of carbon materials, researchers developed binary or multi-heteroatom doped carbon materials to adjust the d-orbitals and optimize the electronic structure (Du et al., 2019; Ling et al., 2019; Kou et al., 2020). Ang et al. (2016) reported the formation of layered $\mathrm{Mo}_{2} \mathrm{C}$ by carburizing of molybdenum oxide/phenol/thioacetamide hybrids, followed by solvent stripping of layered $\mathrm{Mo}_{2} \mathrm{C}$ to further form N/S co-doped molybdenum carbide nanosheets. The synthesized nanosheet has an ultrathin thickness $(1 \mathrm{~nm})$ and a large specific surface area $\left(139 \mathrm{~m}^{2} \mathrm{~g}^{-1}\right)$. The incorporated $\mathrm{N}$ and S effectively improve the wettability of the material. Wang 
et al. (2018a) synthesized NP- $\mathrm{Mo}_{2} \mathrm{C}$ by direct carbonization. Theoretical calculations show that the doping of heteroatoms into carbon promotes the transfer of electrons in the catalyst, and the heteroatoms may also act as catalytic active sites (Gao et al., 2019; Singh et al., 2019). Owing to the synergistic coupling, the double doping of the $\mathrm{N}, \mathrm{P}$ heteroatoms in $\mathrm{Mo}_{2} \mathrm{C}$ can remarkably improve the intrinsic activity of each active site.

\section{Hierarchical Porous Molybdenum Carbide-Based Heterostructure}

Heterostructured hybrids have shown superior electrochemical performance compared to the corresponding single components (Liang et al., 2019; Yao et al., 2019). Through the interface electron transfer in a heterostructure, a large number of interfaces between multiple components can induce optimization of the electronic configuration (Wang et al., 2019d; He et al., 2020). Therefore, constructing heterojunction is an effective way to optimize the free energy of hydrogen adsorption.

The engineering design of molybdenum carbide-based heterostructures provides a new perspective for electrocatalysis. For example, heterostructures of $\mathrm{Mo}-\mathrm{Mo}_{2} \mathrm{C}$ (Dong et al., 2018), $\mathrm{Mo}_{2} \mathrm{C}-\mathrm{Mo}_{2} \mathrm{~N}$ (Chen et al., 2013), $\mathrm{MoP} @ \mathrm{Mo}_{2} \mathrm{C}$ (Huang et al., 2018), and $\left(\mathrm{Mo}_{2} \mathrm{C}\right)_{\mathrm{x}}-(\mathrm{WC})_{1-\mathrm{x}}-\mathrm{QDs}$ (Huo et al., 2017). The synergistic effect of the interface portion exhibits superior HER performance over the single component molybdenum carbide. Dong et al. (2018) obtained a new Mo-rich molybdenum carbide-based electrocatalyst $\left(\mathrm{Mo}-\mathrm{Mo}_{2} \mathrm{C}\right)$ by calcining $\mathrm{Mo}_{3} \mathrm{O}_{10}\left(\mathrm{C}_{6} \mathrm{H}_{8} \mathrm{~N}\right)_{2} \bullet 2 \mathrm{H}_{2} \mathrm{O}$ precursor (Figure 1F). The overpotential of the $\mathrm{Mo}-\mathrm{Mo}_{2} \mathrm{C}$ hydrogen evolution reaction is only $67 \mathrm{mV}$, and the Tafel slope is as low as $55 \mathrm{mV} / \mathrm{dec}$. Its excellent HER performance can be attributed to the improvement of the internal charge transfer ability of the catalyst.

Recently, Huang et al. (2019a) constructed a $\mathrm{Mo}_{2} \mathrm{C} / \mathrm{VC}$ heterostructure. The $\mathrm{CO}_{2}$ decomposed from $\mathrm{Mg}$ and $\mathrm{NaHCO}_{3}$ reacts at high temperature to generate a three-dimensional carbon network. At the same time, the micro-scale precursor $\mathrm{V}_{2} \mathrm{MoO}_{8}$ is broken into two-phase materials $\mathrm{Mo}_{2} \mathrm{C}$ and $\mathrm{VC}$ that are not completely separated and embedded in the threedimensional carbon network. The three-dimensional conductive carbon network and the cross-linked structure fully provide electron transportability and structural stability. $\mathrm{Mo}_{2} \mathrm{C}$ has strong

\section{REFERENCES}

Amrute1, A. P., Łodziana, Z., Schreyer, H., Weidenthaler, C., and Schüth, F. (2019). High-surface-area corundum by mechanochemically induced phase transformation of boehmite. Science 366, 485-489. doi: 10.1126/science.aaw9377

Ang, H., Tan, H. T., Luo, Z. M., Zhang, Y., Guo, Y. Y., Guo, G., et al. (2016). Hydrophilic nitrogen and sulfur co-doped molybdenum carbide nanosheets for electrochemical hydrogen evolution. Small 11, 6278-6284. doi: 10.1002/smll.201502106

Cao, Q., Zhao, L., Wang, A., Yang, L., Lai, L., Wang, Z., et al. (2019). Tailored synthesis of $\mathrm{Zn}-\mathrm{N}$ co-doped porous $\mathrm{MoC}$ nanosheets towards efficient hydrogen evolution. Nanoscale 11, 1700-1709. doi: 10.1039/C8NR0 7463A hydrogen adsorption capacity, while VC has strong hydrogen desorption capacity, so single component $\mathrm{Mo}_{2} \mathrm{C} @ \mathrm{C}$ and VC@C exhibit poor hydrogen evolution reactivity, while $\mathrm{Mo}_{2} \mathrm{C} / \mathrm{VC} @ \mathrm{C}$ shows rapid adsorption capacity and rapid desorption kinetics. Based on the combination of experiment and theory, this experiment proposes that the method of preparing a rich interface structure by phase separation is a way to efficiently prepare high performance catalyst. This approach can be extended to other highly efficient heterogeneous catalysts and different energy sources in the future.

\section{DISCUSSION}

In summary, molybdenum carbide-based materials are an ideal HER material. In this review, recent developments in the structural design and electronic regulation of molybdenum-based catalysts are illustrated. Template method, morphology-conserved transformations method, and secondary conversion of organic-inorganic hybrid materials method are effective strategies for synthesizing various molybdenum carbide-based materials. By compounding with a conductive carrier, element doping and designing a heterojunction can achieve electronic optimization of HER kinetics, greatly improving catalyst activity and stability. In practical applications, material combinations and properties, flexible selection of synthesis methods and performance control methods can synergistically achieve highly efficient catalysts. However, the large-scale application of electrolyzed water for hydrogen evolution still has a long way to go. In combination with the rapid development of molybdenum carbide in electrocatalytic hydrogen evolution in recent years. Future research on molybdenum carbide catalysts may focus on the development of efficient new synthetic methods, the development of molybdenum carbide hydrogen evolution devices, mechanism research, standardized test and the mining and understanding of structure-activity relationships.

\section{AUTHOR CONTRIBUTIONS}

All authors listed have made a substantial, direct and intellectual contribution to the work, and approved it for publication. atoms supported on MOF-derived N-doped Carbon for robust electrochemical hydrogen evolution. Adv. Mater. 30:1800396. doi: 10.1002/adma.201800396

Chen, W.-F., Wang, C.-H., Sasaki, K., Marinkovic, N., Xu, W., Muckerman, J. T., et al. (2013). Highly active and durable nanostructured molybdenum carbide electrocatalysts for hydrogen production. Energy Environ. Sci. 6, 943-951. doi: 10.1039/C2EE23891H

Chen, Y., Li, Z., Zhu, Y., Sun, D., Liu, X., Xu, L., et al. (2019). Atomic Fe dispersed on $\mathrm{N}$-doped carbon hollow nanospheres for high-efficiency electrocatalytic oxygen reduction. Adv. Mater. 31:1806312. doi: 10.1002/adma.201806312

Cheng, Z., Fu, Q., Han, Q., Xiao, Y., Liang, Y., Zhao, Y., et al. (2018). A type of $1 \mathrm{~nm}$ molybdenum carbide confined within carbon nanomesh as highly efficient bifunctional electrocatalyst. Adv. Funct. Mater. 28:1705967. doi: $10.1002 /$ adfm.201705967 
Cui, Q., Chen, C., Yu, C., Lu, T., Long, H., Yan, S., et al. (2020). Effect of molybdenum particles on thermal and mechanical properties of graphite flake/copper composites. Carbon 161, 169-180. doi: 10.1016/j.carbon.2020.01.059

Dhakshinamoorthy, A., Asiri, A. M., and Garcia, H. (2019). 2D Metal-organic frameworks as multifunctional materials in heterogeneous catalysis and electro/photocatalysis. Adv. Mater. 31:1900617. doi: 10.1002/adma.201900617

Dong, J., Wu, Q., Huang, C., Yao, W., and Xu, Q. (2018). Cost effective Mo rich $\mathrm{Mo}_{2} \mathrm{C}$ electrocatalysts for hydrogen evolution reaction. J. Mater. Chem. A 6, 10028-10035. doi: 10.1039/C8TA02550A

Du, R., Jin, X. Y., Hübner, R., Fan, X. L., Hu, Y., and Eychmüller, A. (2019). Engineering self-supported noble metal foams toward electrocatalysis and beyond. Adv. Energy Mater. 10:1901945. doi: 10.1002/aenm.201901945

Feng, Q., Zhao, S., Xu, Q., Chen, W., Tian, S., Wang, Y., et al. (2019). Mesoporous nitrogen-doped carbon-nanosphere-supported isolated single-atom Pd catalyst for highly efficient semihydrogenation of Acetylene. Adv. Mater. 31:1901024. doi: 10.1002/adma.201901024

Gao, K., Wang, B., Tao, L., Cunning, B. V., Zhang, Z. P., Wang, S. Y., et al. (2019). Efficient metal-free electrocatalysts from N-doped carbon nanomaterials: mono-doping and Co-doping. Adv. Mater. 31:1805121. doi: 10.1002/adma.201805121

Gao, Q., Zhang, C., Wang, S., Shen, W., Zhang, Y., Xu, H., et al. (2010). Preparation of supported $\mathrm{Mo}_{2} \mathrm{C}$-based catalysts from organic-inorganic hybrid precursor for hydrogen production from methanol decomposition. Chem. Commun. 46, 6494-6496. doi: 10.1039/c0cc01430c

Garzón-Tovar, L., Pérez-Carvajal, J., Yazdi, A., Hernández-Muñoz, J., Tarazona, P., Imaz, I., et al. (2019). A MOF@COF composite with enhanced uptake through interfacial pore generation. Angew. Chem. 131, 9612-9616. doi: 10.1002/ange.201904766

Guo, J., Huo, J., Liu, Y., Wu, W., Wang, Y., Wu, M., et al. (2019). Nitrogen-doped porous carbon supported nonprecious metal single-atom electrocatalysts: from synthesis to application. Small Methods 3:1900159. doi: 10.1002/smtd.201900159

Han, X., Zhang, W., Ma, X., Zhong, C., Zhao, N., Hu, W., et al. (2019). Identifying the activation of bimetallic sites in $\mathrm{NiCo}_{2} \mathrm{~S}_{4} @ g-\mathrm{C}_{3} \mathrm{~N}_{4}-\mathrm{CNT}$ hybrid electrocatalysts for synergistic oxygen reduction and evolution. Adv. Mater. 31:1808281. doi: 10.1002/adma.201808281

He, L., Zhang, W., Mo, Q., Huang, W., Yang, L., and Gao, Q. (2020). Molybdenum carbide-oxide heterostructures: in situ surface reconfiguration toward efficient electrocatalytic hydrogen evolution. Angew. Chem. Int. Ed. 59, 3544-3548. doi: 10.1002/anie.201914752

Hou, J., Wu, Y., Zhang, B., Cao, S., Li, Z., and Sun, L. (2019). Rational design of nanoarray architectures for electrocatalytic water splitting. Adv. Funct. Mater. 29:1808367. doi: 10.1002/adfm.201808367

Hsieha, Y.-Y., Fang, Y., Daum, J., Kanakaraj, S. N., Zhang, G., Mishra, S., et al. (2019). Bio-inspired, nitrogen doped CNT-graphene hybrid with amphiphilic properties as a porous current collector for lithium-ion batteries. Carbon 145, 677-689. doi: 10.1016/j.carbon.2019.01.055

Huang, C., Miao, X., Pi, C., Gao, B., Zhang, X., Qin, P., et al. (2019a). $\mathrm{Mo}_{2} \mathrm{C} / \mathrm{VC}$ heterojunction embedded in graphitic carbon network: an advanced electrocatalyst for hydrogen evolution. Nano Energy 60, 520-526. doi: 10.1016/j.nanoen.2019.03.088

Huang, C., Peng, J., Wan, S., Du, Y., Dou, S., Wagner, H. D., et al. (2019b). Ultra-tough inverse artificial nacre based on epoxy-graphene by freeze-casting. Angew. Chem. Int. Ed. 58, 7636-7640. doi: 10.1002/anie.201902410

Huang, H., Yu, C., Huang, H., Guo, W., Zhang, M., Han, X., et al. (2019c). Microwave-assisted ultrafast synthesis of molybdenum carbide nanoparticles grown on carbon matrix for efficient hydrogen evolution reaction. Small Methods 3:1900259. doi: 10.1002/smtd.201900259

Huang, J., Xiao, Y., Peng, Z., Xu, Y., Li, L., Tan, L., et al. (2019d). $\mathrm{Co}_{3} \mathrm{O}_{4}$ supraparticle-based bubble nanofiber and bubble nanosheet with remarkable electrochemical performance. Adv. Sci. 6:1900107. doi: 10.1002/advs.201900107

Huang, Y., Ge, J., Hu, J., Zhang, J., Hao, J., Wei, Y., et al. (2018). Nitrogen-doped porous molybdenum carbide and phosphide hybrids on a carbon matrix as highly effective electrocatalysts for the hydrogen evolution reaction. Adv. Energy Mater. 8:1701601. doi: 10.1002/aenm.2017 01601
Huo, J., Chen, Y., Liu, Y., Guo, J., Lu, L., Li, W., et al. (2019). Bifunctional iron nickel phosphide nanocatalysts supported on porous carbon for highly efficient overall water splitting. Sust. Mater. Technol. 22:e00117. doi: 10.1016/j.susmat.2019.e00117

Huo, L., Liu, B., Gao, Z., and Zhang, J. (2017). 0D/2D heterojunctions of molybdenum carbide-tungsten carbide quantum dots/ $\mathrm{N}$-doped graphene nanosheets as superior and durable electrocatalysts for hydrogen evolution reaction. J. Mater. Chem. A 5, 18494-18501. doi: 10.1039/C7TA02864D

Jia, J., Xiong, T., Zhao, L., Wang, F., Liu, H., Hu, R., et al. (2017). Ultrathin $\mathrm{N}$-doped $\mathrm{Mo}_{2} \mathrm{C}$ nanosheets with exposed active sites as efficient electrocatalyst for hydrogen evolution reactions. ACS Nano 11, 12509-12518. doi: 10.1021/acsnano.7b06607

Khaselev, O., and Turner, J. A. (1998). A monolithic photovoltaicphotoelectrochemical device for hydrogen production via water splitting. Science 280, 425-427. doi: 10.1126/science.280.5362.425

Kim, S., Choi, C., Hwang, J., Park, J., Jeong, J., Jun, H., et al. (2020). Interaction mediator assisted synthesis of mesoporous molybdenum carbide: mo-valence state adjustment for optimizing hydrogen evolution. ACS Nano 14, 4988-4999. doi: 10.1021 acsnano.0c01285

Kou, Z., Wang, T., Cai, Y., Guan, C., Pu, Z., Zhu, C., et al. (2018). Ultrafine molybdenum carbide nanocrystals confined in carbon foams via a colloidconfinement route for efficient hydrogen production. Small Methods 2:1700396. doi: 10.1002/smtd.201700396

Kou, Z., Yu, Y., Liu, X., Gao, X., Zheng, L., Zou, H., et al. (2020). Potentialdependent phase transition and Mo-enriching surface reconstruction of $\gamma$ $\mathrm{CoOOH}$ in heterostructured $\mathrm{Co}-\mathrm{Mo} 2 \mathrm{C}$ precatalyst enable water oxidation. ACS Catal. 10, 4411-4419. doi: 10.1021/acscatal.0c00340

Li, B., Ma, J.-G., and Cheng, P. (2019a). Integration of metal nanoparticles into metal-organic frameworks for composite catalysts: design and synthetic strategy. Small 15:1804849. doi: 10.1002/smll.201804849

Li, M., Zhu, Y., Wang, H., Wang, C., Pinna, N., Lu, X., et al. (2019b). Ni strongly coupled with $\mathrm{Mo}_{2} \mathrm{C}$ encapsulated in nitrogen-doped carbon nanofibers as robust bifunctional catalyst for overall water splitting. Adv. Energy Mater 9:1803185. doi: 10.1002/aenm.201803185

Li, Y., Tan, X., Chen, S., Bo, X., Ren, H., Smith, S. C., et al. (2019c). Processable surface modification of nickel-heteroatom $(\mathrm{N}, \mathrm{S})$ bridge sites for promoted alkaline hydrogen evolution. Angew. Chem. 131, 471-476. doi: 10.1002/ange.201808629

Li, Z., Zhang, L., Chen, X., Li, B. L., Wang, H., and Li, Q. (2019d). Threedimensional graphene-like porous carbon nanosheets derived from molecular precursor for high-performance supercapacitor application. Electrochim. Acta 296, 8-17. doi: 10.1016/j.electacta.2018.11.002

Liang, Q., Zhong, L., Du, C., Luo, Y., Zhao, J., Zheng, Y., et al. (2019). Interfacing epitaxial dinickel phosphide to $2 \mathrm{D}$ nickel thiophosphate nanosheets for boosting electrocatalytic water splitting. ACS Nano 13, 7975-7984. doi: 10.1021/acsnano.9b02510

Liao, L., Wang, S., Xiao, J., Bian, X., Zhang, Y., Scanlon, M. D., et al. (2014). A nanoporous molybdenum carbide nanowire as an electrocatalyst for hydrogen evolution reaction. Energy Environ. Sci. 7, 387-392. doi: 10.1039/C3EE42441C

Lin, H., Liu, N., Shi, Z., Guo, Y., Tang, Y., and Gao, Q. (2016a). Cobalt-doping in molybdenum-carbide nanowires toward efficient electrocatalytic hydrogen evolution. Adv. Funct. Mater. 26, 5590-5598. doi: 10.1002/adfm.201600915

Lin, H., Shi, Z., He, S., Yu, X., Wang, S., Gao, Q., et al. (2016b). Heteronanowires of $\mathrm{MoC}-\mathrm{Mo}_{2} \mathrm{C}$ as efficient electrocatalysts for hydrogen evolution reaction. Chem. Sci. 7, 3399-3405. doi: 10.1039/C6SC00077K

Lin, H., Zhang, W., Shi, Z., Che, M., Yu, X., Tang, Y., et al. (2017a). Cover picture: electrospinning hetero-nanofibers of $\mathrm{Fe}_{3} \mathrm{C}-\mathrm{Mo}_{2} \mathrm{C} /$ nitrogen-doped-carbon as efficient electrocatalysts for hydrogen evolution. ChemSusChem 10, 2597-2640. doi: $10.1002 /$ cssc. 201700207

Lin, L., Zhou, W., Gao, R., Yao, S., Zhang, X., Xu, W., et al. (2017b). Lowtemperature hydrogen production from water and methanol using $\mathrm{Pt} / \alpha-\mathrm{MoC}$ catalysts. Nature 544, 80-83. doi: 10.1038/nature21672

Ling, T., Zhang, T., Ge, B., Han, L., Zheng, L., Lin, F., et al. (2019). Well-dispersed nickel-and zinc-tailored electronic structure of a transition metal oxide for highly active alkaline hydrogen evolution reaction. Adv. Mater. 31:1807771. doi: 10.1002/adma.201807771

Liu, T., Zhang, M., Wang, Y. L., Wang, Q. Y., Lv, C., Liu, K. X., et al. (2018). Engineering the surface/interface of horizontally oriented carbon nanotube 
macrofilm for foldable lithium-ion battery withstanding variable weather. $A d v$. Energy Mater. 8:1802349. doi: 10.1002/aenm.201802349

Liu, Y., Li, X., Shen, W., Dai, Y., Kou, W., Zheng, W., et al. (2019). Multishelled transition metal-based microspheres: synthesis and applications for batteries and supercapacitors. Small 15:1804737. doi: 10.1002/smll.201804737

Lu, X. F., Yu, L., Zhang, J. T., and Lou, X. W. (2019). Ultrafine dualphased carbide nanocrystals confined in porous nitrogen-doped carbon dodecahedrons for efficient hydrogen evolution reaction. Adv. Mater. 31:1900699. doi: 10.1002/adma.201900699

Lyu, F., Zeng, S., Sun, Z., Qin, N., Cao, L., Wang, Z., et al. (2019). Lamellarly stacking porous $\mathrm{N}, \mathrm{P}$ co-doped $\mathrm{Mo}_{2} \mathrm{C} / \mathrm{C}$ nanosheets as high performance anode for lithium-ion batteries. Small 15:1805022. doi: 10.1002/smll.201805022

Ma, Y.-Y., Lang, Z.-L., Yan, L.-K., Wang, Y.-H., Tan, H.-Q., Feng, K., et al. (2018). Highly efficient hydrogen evolution triggered by a multiinterfacial Ni/WC hybrid electrocatalyst. Energy Environ. Sci. 11, 2114-2123. doi: 10.1039/C8EE01129J

Martinez, U., Babu, S. K., Holby, E. F., Chung, H. T., Yin, X., and Zelenay, P. (2019). Progress in the development of Fe-based PGM-free electrocatalysts for the oxygen reduction reaction. Adv. Mater. 31:1806545. doi: 10.1002/adma.201806545

Niu, S., Jiang, W.-J., Tang, T., Yuan, L.-P., Luo, H., and Hu, J.-S. (2019). Autogenous growth of hierarchical $\mathrm{NiFe}(\mathrm{OH})_{\mathrm{X}} / \mathrm{FeS}$ nanosheet-on-microsheet arrays for synergistically enhanced high-output water oxidation. Adv. Funct. Mater. 29:1902180. doi: 10.1002/adfm.201902180

Nong, S., Dong, W., Yin, J., Dong, B., Lu, Y., Yuan, X., et al. (2018). Well-dispersed ruthenium in mesoporous crystal $\mathrm{TiO}_{2}$ as an advanced electrocatalyst for hydrogen evolution reaction. J. Am. Chem. Soc. 140, 5719-5727. doi: 10.1021/jacs.7b13736

Pan, L. F., Li, Y. H., Yang, S., Liu, P. F., Yu, M. Q., and Yang, H. G., et al. (2014). Molybdenum carbide stabilized on graphene with high electrocatalytic activity for hydrogen evolution reaction. Chem. Commun. 50, 13135-13137. doi: 10.1039/C4CC05698A

Ryoo, R. (2019). Birth of a class of nanomaterial. Nature 575, 40-41. doi: 10.1038/d41586-019-02835-7

Shi, Z., Nie, K., Shao, Z., Gao, B., Lin, H., Zhang, H., et al. (2017). Phosphorus$\mathrm{Mo}_{2} \mathrm{C} @$ carbon nanowires toward efficient electrochemical hydrogen evolution: composition, structural and electronic regulation. Energy Environ. Sci. 10, 1262-1271.doi: 10.1039/C7EE00388A

Shi, Z., Wang, Y., Lin, H., Zhang, H., Shen, M., Xie, S., et al. (2016). Porous nanoMoC@graphite shell derived from a MOFs-directed strategy: an efficient electrocatalyst for the hydrogen evolution reaction. J. Mater. Chem. A 20164 , 6006-6013. doi: 10.1039/C6TA01900E

Singh, S. K., Takeyasu, K., and Nakamura, J. (2019). Active sites and mechanism of oxygen reduction reaction electrocatalysis on nitrogen-doped carbon materials. Adv. Mater. 31:1804297. doi: 10.1002/adma.201804297

Tan, Y., Xu, C., Chen, G., Fang, X., Zheng, N., and Xie, Q. (2012). Facile synthesis of manganese-oxide-containing mesoporous nitrogen-doped carbon for efficient oxygen reduction. Adv. Funct. Mater. 22, 4584-4591. doi: 10.1002/adfm.201201244

Thompson, B. R., Horozov, T. S., Stoyanov, S. D., and Paunov, V. N. (2019). Hierarchically structured composites and porous materials from soft templates: fabrication and applications. J. Mater. Chem. A 7, 8030-8049. doi: 10.1039/C8TA09750

Wan, C., Regmi, Y. N., and Leonard, B. M. (2014). Multiple phases of molybdenum carbide as electrocatalysts for the hydrogen evolution reaction. Angew. Chem. Int. Ed. 53, 6407-6410. doi: 10.1002/anie.201402998

Wang, D., Liu, T., Wang, J., and Wu, Z. (2018a). N, P (S) co-doped $\mathrm{Mo}_{2} \mathrm{C} / \mathrm{C}$ hybrid electrocatalysts for improved hydrogen generation. Carbon 139, 845-852. doi: 10.1016/j.carbon.2018.07.043

Wang, F., Jiang, J., Wang, K., Zhai, Q., Long, F., Liu, P., et al. (2019a). Hydrotreatment of lipid model for diesel-like alkane using nitrogen-doped mesoporous carbon-supported molybdenum carbide. Appl. Catal. B Environ. 242, 150-160. doi: 10.1016/j.apcatb.2018. 09.077

Wang, H., Xiao, X., Liu, S., Chiang, C.-L., Kuai, X., Peng, C.-K., et al. (2019b). Structural and electronic optimization of $\mathrm{MoS}_{2}$ edges for hydrogen evolution. J. Am. Chem. Soc. 141. 18578-18584. doi: 10.1021/jacs.9b 09932
Wang, H.-M., Wang, X.-H., Zhang, M.-H., Du, X.-Y., Li, W., and Tao, K.-Y. (2007). Synthesis of bulk and supported molybdenum carbide by a single-step thermal carburization method. Chem. Mater. 19, 1801-1807. doi: 10.1021/cm0615471

Wang, M., Wang, W., Qian, T., Liu, S., Li, Y., Hou, Z., et al. (2019c). Oxidizing vacancies in nitrogen-doped carbon enhance air-cathode activity. Adv. Mater. 31:1803339. doi: 10.1002/adma.201803339

Wang, X.-D., Huang, Y.-H., Liao, J.-F., Jiang, Y., Zhou, L., Zhang, X.-Y., et al. (2019d). In situ construction of a $\mathrm{Cs}_{2} \mathrm{SnI}_{6}$ perovskite nanocrystal/SnS 2 nanosheet heterojunction with boosted interfacial charge transfer. J. Am. Chem. Soc. 141, 13434-13441. doi: 10.1021/jacs.9b04482

Wang, X.-L., Dong, L.-Z., Qiao, M., Tang, Y.-J., Liu, J., Li, Y., et al. (2018b). Exploring the performance improvement of the oxygen evolution reaction in a stable bimetal-organic framework system. Angew. Chem. Int. Ed. 57, 9660-9664. doi: 10.1002/anie.201803587

Wang, Y., Adekoya, D., Sun, J., Tang, T., Qiu, H., Xu, L., et al. (2019e). Manipulation of edge-site $\mathrm{Fe}-\mathrm{N}_{2}$ moiety on holey $\mathrm{Fe}, \mathrm{N}$ codoped graphene to promote the cycle stability and rate capacity of Li-S batteries. Adv. Funct. Mater. 29:1807485. doi: 10.1002/adfm.201807485

Wang, Y., Wang, Y., Kang, W., Cao, D., Li, C., Cao, D., et al. (2019f). TiO coated interlayer-expanded $\mathrm{MoSe}_{2} /$ phosphorus-doped carbon nanospheres for ultrafast and ultralong cycling sodium storage. Adv. Sci. 6:1801222. doi: 10.1002/advs.201801222

Wu, C., Liu, D., Li, H., Li, J., et al. (2018a). Molybdenum carbide-decorated metallic cobalt@ nitrogen-doped carbon polyhedrons for enhanced electrocatalytic hydrogen evolution. Small 14:1704227. doi: 10.1002/smll.201704227

Wu, H., Li, Y., Ren, J., Rao, D., Zheng, Q., Zhou, L., et al. (2019). CNTassembled dodecahedra core@ nickel hydroxide nanosheet shell enabled sulfur cathode for high-performance lithium-sulfur batteries. Nano Energy 55, 82-92. doi: 10.1016/j.nanoen.2018.10.061

Wu, H. B., Xia, B. Y., Yu, L., Yu, X.-Y., and Lou, X. W. (2015). Porous molybdenum carbide nano-octahedrons synthesized via confined carburization in metalorganic frameworks for efficient hydrogen production. Nat. Commun. 6:6512. doi: 10.1038/ncomms7512

Wu, Z., Zou, Z., Huang, J., Gao, F., et al. (2018b). Fe-doped NiO mesoporous nanosheets array for highly efficient overall water splitting. J. Catal. 358, 243-252. doi: 10.1016/j.jcat.2017.12.020

Wu, Z.-Y., Hu, B.-C., Wu, P., Liang, H.-W., Yu, Z.-L., Lin, Y., et al. (2016). $\mathrm{Mo}_{2} \mathrm{C}$ nanoparticles embedded within bacterial cellulose-derived 3D N-doped carbon nanofiber networks for efficient hydrogen evolution. Npg Asia Mater. 8:e288. doi: 10.1038/am.2016.87

Xiong, H., Wu, L., Liu, Y., Gao, T., Li, K., Long, Y., et al. (2019). Controllable synthesis of mesoporous $\mathrm{TiO}_{2}$ polymorphs with tunable crystal structure for enhanced photocatalytic $\mathrm{H}_{2}$ production. Adv. Energy Mater. 9:1901634. doi: 10.1002/aenm.201901634

Xue, Z., Wang, P., Peng, A., and Wang, T. (2019). Architectural design of self-assembled hollow superstructures. Adv. Mater. 31:1801441. doi: 10.1002/adma.201801441

Yang, C., Guo, K., Yuan, D., Cheng, J., and Wang, B. (2020). Unraveling reaction mechanisms of $\mathrm{Mo} 2 \mathrm{C}$ as cathod catalyst in Li-Co2 battery. J. Am. Chem. Soc. 142, 6983-6990. doi: 10.1021/jacs.9b12868

Yang, L., Shui, J., Du, L., Shao, Y., Liu, J., Dai, L., et al. (2019). Carbon-based metalfree ORR electrocatalysts for fuel cells: past, present, and future. Adv. Mater. 31:1804799. doi: 10.1002/adma.201804799

Yao, N., Li, P., Zhou, Z., Zhao, Y., Cheng, G., Chen, S., et al. (2019). Synergistically tuning water and hydrogen binding abilities over $\mathrm{Co}_{4} \mathrm{~N}$ by $\mathrm{Cr}$ doping for exceptional alkaline hydrogen evolution electrocatalysis. Adv. Energy Mater. 9:1902449. doi: 10.1002/aenm.201902449

Yu, B., Yang, D., Hu, Y., He, J., Chen, Y., and He, W. (2019). $\mathrm{Mo}_{2} \mathrm{C}$ nanodots anchored on N-doped porous CNT microspheres as electrode for efficient Li-ion storage. Small Methods 3:1800287. doi: 10.1002/smtd.201800287

Yuan, S., Xu, S., Liu, Z., Huang, G., Zhang, C., Ai, J., et al. (2019). Ultrasmall molybdenum carbide nanoparticles in situ entrapped in mesoporous carbon spheres as efficient catalysts for hydrogen evolution. Chem CatChem 11, 2643-2648. doi: 10.1002/cctc.201900324

Zhang, J., Liu, J., Xi, L., Yu, Y., Chen, N., Sun, S., et al. (2018). Singleatom $\mathrm{Au} / \mathrm{NiFe}$ layered double hydroxide electrocatalyst: probing the origin of activity for oxygen evolution reaction. J. Am. Chem. Soc. 140, 3876-3879. doi: $10.1021 /$ jacs.8b00752 
Zhang, L., Doyle-Davis, K., and Sun, X. (2019). Pt-based electrocatalysts with high atom utilization efficiency: from nanostructures to single atoms. Energy Environ. Sci. 12, 492-517. doi: 10.1039/C8EE02939C

Zhao, Q., Zhu, Q., Miao, J., Zhang, P., Wan, P., He, L., et al. (2019a). Flexible 3D porous MXene foam for high-performance lithium-lon batteries. Small 15:1904293. doi: 10.1002/smll.201904293

Zhao, X., Sun, W., Geng, D., Fu, W., Dan, J., Xie, Y., et al. (2019b). Edge segregated polymorphism in 2D molybdenum carbide. Adv. Mater. 31:1808343. doi: 10.1002/adma.201808343

Zhao, Z., Chen, C., Liu, Z., Huang, J., Wu, M., Liu, H., et al. (2019c). Pt-based nanocrystal for electrocatalytic oxygen reduction. Adv. Mater. 31:1808115. doi: 10.1002/adma.201808115

Zhong, H., Yang, C., Fan, L., Fu, Z., Yang, X., Wang, X., et al. (2019). Dyadic promotion of photocatalytic aerobic oxidation via the Mott-Schottky effect enabled by nitrogen-doped carbon from imidazolium-based ionic polymers. Energy Environ. Sci. 12, 418-426. doi: 10.1039/C8EE02727G

Conflict of Interest: The authors declare that the research was conducted in the absence of any commercial or financial relationships that could be construed as a potential conflict of interest.

Copyright (C) $2020 \mathrm{Liu}, \mathrm{Huo}, \mathrm{Guo}, \mathrm{Lu}$, Shen, Chen, Liu and Liu. This is an open-access article distributed under the terms of the Creative Commons Attribution License (CC $B Y)$. The use, distribution or reproduction in other forums is permitted, provided the original author(s) and the copyright owner(s) are credited and that the original publication in this journal is cited, in accordance with accepted academic practice. No use, distribution or reproduction is permitted which does not comply with these terms. 